Research Article

\title{
Effects of Curing Time on the Mechanical Property and Microstructure Characteristics of Metakaolin-Based Geopolymer Cement-Stabilized Silty Clay
}

\author{
Zhang Rong-rong $\mathbb{i D}^{1,2,3}$ and Ma Dong-dong $\mathbb{i D}^{1,2,3}$ \\ ${ }^{1}$ Research Center of Mine Underground Engineering, Ministry of Education, Anhui University of Science and Technology, \\ Huainan 232001, China \\ ${ }^{2}$ School of Civil Engineering and Architecture, Anhui University of Science and Technology, Huainan, China \\ ${ }^{3}$ State Key Laboratory of Mining Response and Disaster Prevention and Control in Deep Coal Mine, \\ Anhui University of Science and Technology, Huainan, Anhui 232001, China \\ Correspondence should be addressed to Ma Dong-dong; dongdonm@126.com
}

Received 6 May 2019; Revised 18 August 2019; Accepted 20 September 2019; Published 14 February 2020

Academic Editor: Antonio Boccaccio

Copyright (C) 2020 Zhang Rong-rong and Ma Dong-dong. This is an open access article distributed under the Creative Commons Attribution License, which permits unrestricted use, distribution, and reproduction in any medium, provided the original work is properly cited.

\begin{abstract}
Metakaolin (MK), which has a fine particle size and higher activity in high alkaline environments, has been widely used in the fields of soil treatment engineering to stabilize soils. MK is used to replace part of ordinary Portland cement (OPC) with $0: 15,2: 13,4: 11$ and $6: 9$ mass ratios of MK to OPC in this study. The mechanical property (e.g. stress-strain relationship, strength, and deformation performance) and microstructure characteristics of MK-based geopolymer cemented silty clay are investigated using unconfined compressive strength (UCS), nuclear magnetic resonance (NMR), and scanning electronic microscopy (SEM) tests. In addition, strength increase coefficient $\left(\zeta_{\mathrm{s}}\right)$ and elasticity modulus increase coefficient $\left(\zeta_{\mathrm{e}}\right)$ are defined to evaluate the effects of curing time on the mechanical property of MK-based geopolymer cemented silty clay. Moreover, the relationships among porosity, UCS, and $E_{50}$ of MK-cemented silty clay are studied. By incorporating $2 \% \mathrm{MK}$, the UCS and $E_{50}$ of MK-cemented silty clay at $28 \mathrm{~d}$ are 1.32 and 1.30 times compared with MK0 group, respectively. The increase rate of UCS and $E_{50}$ from $1 \mathrm{~d}$ to $7 \mathrm{~d}$ is faster compared with that from $7 \mathrm{~d}$ to $28 \mathrm{~d}$. Furthermore, the microstructure of the sample modified by $2 \% \mathrm{MK}$ is most homogeneous and dense. Finally, the optimistic mass ratio between $\mathrm{MK}$ and cement is $2: 13$ for silty clay in this test condition.
\end{abstract}

\section{Introduction}

Cement soil reinforcement technique has been accepted worldwide in the areas of foundation engineering, slope reinforcement, road construction, and rammed earth wall engineering for many years [1-5]. It has been proved as an effective reinforcement technique with many advantages, such as high usage rate of origin soil, low cost, and convenient construction $[6,7]$. However, in the cement production process, about $900 \mathrm{~kg} \mathrm{CO}_{2}$ will be emitted into the atmosphere per tonner of cement which contributed to global warming and climate change [8-11]. Therefore, some supplementary cementitious materials (e.g., metakaolin, fly ash, slag, and nanosilica) have been used for replacing part of cement to reduce $\mathrm{CO}_{2}$ emission associated with cement production [12-14].

As a typical pozzolanic material, metakaolin (MK) is an amorphous aluminosilicate compound produced by calcinations of pure kaolinite at $500^{\circ} \mathrm{C}$ to $550^{\circ} \mathrm{C}$ [15], which has high activity and has attracted increasing attention in recent years that could partly replace ordinary Portland cement [16]. Compared with other supplementary cementitious materials, MK has many advantages, including higher activity, larger specific surface, and finer particle size [17]. Studies have emerged that offer contradictory findings about the effects of MK content on physical and mechanical properties of cement soil and concrete materials and acquired abundant accomplishment [15, 16, 18-23]. Wu et al. 
[15] studied the effect of MK contents on the strength performance of cement-modified soil, and test results reveal that both the unconfined compression and splitting tensile strengths are improved, and the suitable ratio of MK to cement ranges from $1 / 3$ to $1 / 2$. Moreover, the addition of MK led to a higher quantity of hydration products and denser microporosity distribution according to X-ray diffraction (XRD), scanning electronic microscopy (SEM), thermogravimetric analysis (TGA), and mercury intrusion porosimetry (MIP) test results, and a similar series of experiment results are also found [19]. Wang et al. [22] investigated the effects of curing time and coal-metakaolin content on the properties of cemented sandy soils, and test results indicate that the unconfined compression strength at $28 \mathrm{~d}$ was improved by $1.68-2.18$ times by incorporating coalmetakaolin. Furthermore, similar tests were performed on cemented silty soil, and the optimum mass ratio of coalmetakaolin to cement is between $1: 6.5$ and $1: 4$ [23]. Experimental and theoretical results mentioned above show that MK can significantly improve the strength property of concrete and cemented soils at the appropriate proportion. Meanwhile, the optimum mass ratio of MK to cement is affected by the soil and MK types and test conditions including purity and grain sizes.

Curing time has a significant influence on chemical reaction degree between cement, $M K$, and water [24, 25], which affects the strength and deformation properties of MK-based geopolymer cemented soil. Specifically, MKbased geopolymer cemented soil requires sufficient time to achieve high mechanical properties and elevated durability. However, by summarizing the theoretical and experimental studies achievements, it can be found that researches mainly concentrate on the MK content and its improvement mechanisms, but there are still insufficient data for effect of curing time, especially at an early curing age. In addition, studies focused on microstructure characteristics of MK cement soil under different curing times are relatively insufficient. Hence, the objective of this research is to investigate the effects of curing time on mechanical property (i.e., unconfined compressive strength, elasticity modulus, and stress-strain relationship) and microstructure characteristic of cement-stabilized soil incorporate with different MK contents. The mass ratio of binder (cement and MK) to dry soil is $15 \%$ in this test. Finally, SEM and nuclear magnetic resonance (NMR) techniques are used to study the porosity and microstructure characteristic of MK cement silty clay with $26.5 \%$ water content, to analyze the internal microstructure change of MK-cemented silty clay under different MK contents (i.e., $0 \%, 2 \%, 4 \%$, and $6 \%$ ) and curing times (i.e., $1 \mathrm{~d}, 3 \mathrm{~d}, 7 \mathrm{~d}, 14 \mathrm{~d}$, and $28 \mathrm{~d}$ ).

\section{Materials and Experimental Methods}

2.1. Materials. The soil used in this study was collected from a foundation reinforce engineering in Huainan (Anhui, China). The physical properties of the soil are shown in Table 1. According to the Chinese National Standard GB 50021-2001 (2009 version) [26], it was categorized as "silty clay."
TABle 1: Physical properties of soil.

\begin{tabular}{lc}
\hline Properties & Values \\
\hline Liquid limit $(\%)$ & 29.5 \\
Plastic limit $(\%)$ & 43.6 \\
Plasticity index & 14.1 \\
Medium sand content $(0.425 \mathrm{~mm}<$ diameter & $16.7 \%$ \\
$<2 \mathrm{~mm})$ & $27.1 \%$ \\
Fine sand content $(0.075 \mathrm{~mm}<$ diameter $<0.425 \mathrm{~mm})$ & $56.2 \%$ \\
Silt and clay content $($ diameter $<0.075 \mathrm{~mm})$ & Silty clay \\
Soil classification-GB $20021($ Chinese standard $)$ & \\
\hline
\end{tabular}

The ordinary Portland cement (OPC) and MK in this experiment were produced by Bagongshan cement plant and Shanghai $\mathrm{HaoFu}$ chemical company, respectively. The chemical compositions of OPC and MK are listed in Table 2. The average particle size, specific surface area, and activity index of MK were $1 \mu \mathrm{m}, 2000 \mathrm{~m}^{2} / \mathrm{kg}$, and 122 , respectively. From Table 2, it was clearly noticed that the main components of $\mathrm{MK}$ were $\mathrm{SiO}_{2}$ and $\mathrm{Al}_{2} \mathrm{O}_{3}$.

2.2. Sample Preparation. The undisturbed silty clay was put in a dryer at $105^{\circ} \mathrm{C}$ for more than $24 \mathrm{~h}$ to constant weight and then crushed and sifted larger size $(2 \mathrm{~mm})$ from the sample. Thereafter, water equal to the original water content (26.5\%) was added continuously to the mixture and mixed for about $30 \mathrm{~min}$, and then the silty clay was stored in a closed container for more than $24 \mathrm{~h}$ to make the soil saturated. In this experiment, $15 \%$ binder (mass ratio of binder to dry soil) was adopted to stabilize the silty clay according to the design guidelines for cemented soil pile established by standard JGJ 79-2012 [27]. The mass ratios of MK to OPC in this test were $0: 15,2: 13,4: 11$, and $6: 9$, respectively, and the corresponding group were designated MK0, MK2, MK4, and MK6, respectively. Sample preparation procedure was as follows: (1) put MK into the silty clay and mix evenly; (2) mix sodium silicate and $\mathrm{NaOH}$ solution (50\% concentration) with the mass ratio of 5.8 to 1 for the preparation of alkali activator [28], and then spray them into the mixture equably with a sprinkling can; and (3) add the calculated cement into the mixture and the corresponding water. The action of alkali activator used in this test can provide alkaline environment for MK to perform a three-dimensional network structure which is composed of silica tetrahedron and alumino-octahedron, as shown in Figure 1.

2.3. Unconfined Compressive Strength (UCS) Test. The final mixture was divided into five portions and put into a cubic mold with dimensions of $70.7 \mathrm{~mm} \times 70.7 \mathrm{~mm} \times 70.7 \mathrm{~mm}$ according to specification for the mix proportion test of cement-mixed soil established by standard JGJ/T 233-2011. To conduct the UCS test, the top of each layer was scratched before adding the next layer to promote suitable bonding. The MK-based geopolymer cemented silty clay samples were removed from the molds after $24 \mathrm{~h}$, and each sample was cured in a standard concrete materials curing room with temperature of $(20 \pm 2)^{\circ} \mathrm{C}$ and humidity of $(95 \pm 2) \%$ [30]. These samples were tested after curing $1 \mathrm{~d}, 3 \mathrm{~d}, 7 \mathrm{~d}, 14 \mathrm{~d}$, and 
TABLE 2: Chemical compositions of OPC and MK.

\begin{tabular}{lccccccccc}
\hline Oxide content (\%) & $\mathrm{SiO}_{2}$ & $\mathrm{Al}_{2} \mathrm{O}_{3}$ & $\mathrm{CaO}$ & $\mathrm{Fe}_{2} \mathrm{O}_{3}$ & $\mathrm{SO}_{3}$ & $\mathrm{MgO}$ & $\mathrm{Na}_{2} \mathrm{O}$ & $\mathrm{K}_{2} \mathrm{O}$ & $\mathrm{TiO}_{2}$ \\
\hline OPC & 17.8 & 5.7 & 67.5 & 3.7 & 2.8 & 1.4 & 0.6 & 0.5 & - \\
$\mathrm{MK}$ & 53.8 & 43.1 & 0.6 & 0.8 & - & 0.2 & 0.2 & 0.1 & 1.2 \\
\hline
\end{tabular}

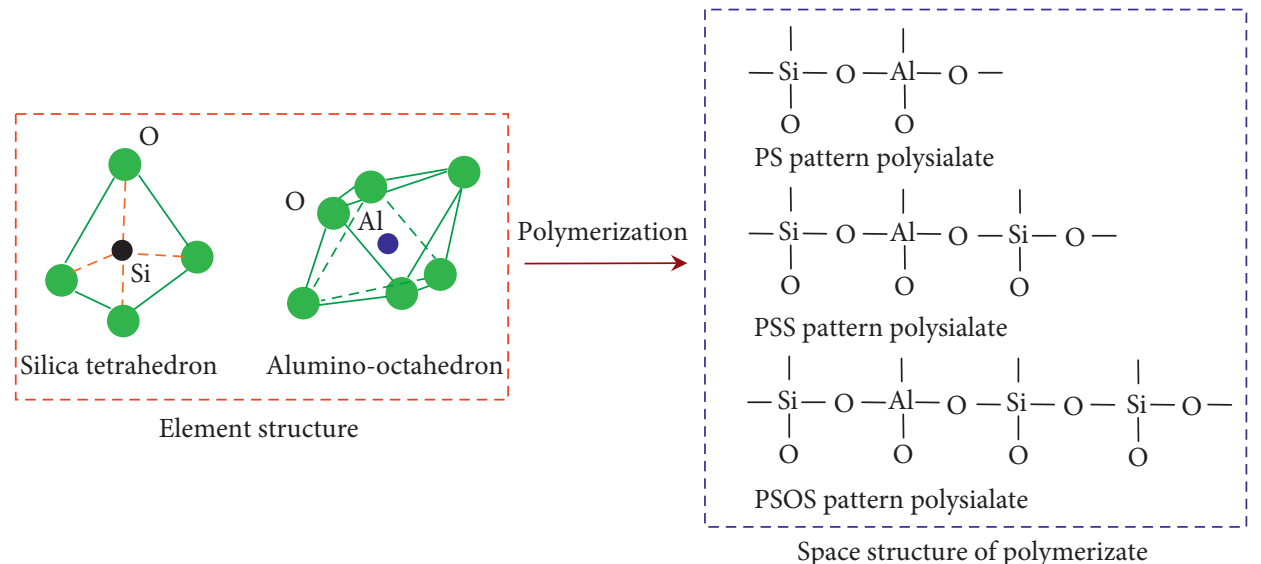

FIGURE 1: Formation of high-performance geopolymer [29].

$28 \mathrm{~d}$ to determine their unconfined compressive strengths. The UCS tests were conducted by an RWS-200 microcomputer controlled electronic universal testing machine at a loading rate of $1 \mathrm{~mm} / \mathrm{min}$. Furthermore, three parallel samples were prepared to improve the test reliability, and test results were considered suitable for presenting if their average error was less than $5 \%$.

2.4. NMR Test. NMR technology has been widely used to obtain the pore structures of cement-based materials [3135], which was conducted to measure the porosity of MKbased geopolymer cemented soil under different test conditions in this test. In NMR tests, dimension of $\Phi 50 \mathrm{~mm} \times 50 \mathrm{~mm}$ is the maximum size for NMR device. The maximum particle diameter for MK-based stabilized clays is the soil particle with $2 \mathrm{~mm}$, and the larger the specimen size, the precise the test results. In addition, considering the possible damage in sample transport process, specimens with the size of $\Phi 50 \mathrm{~mm} \times 25 \mathrm{~mm}$ under different curing times and MK contents are prepared for NMR tests.

2.5. SEM Test. Quanta FEG 650 pattern environmental scanning electron microscope was used to investigate the microstructure characteristic of MK-based geopolymer cemented soil under different $\mathrm{MK}$ contents and curing times, all of the samples were obtained from the central part of complete samples $[36,37]$. These samples were coated with gold for improving their conductivity before imaging. The SEM instrument was operated at $10 \mathrm{kV}$.

\section{Test Results and Discussion}

3.1. Stress-Strain Relationship and Failure Mode. The typical stress-strain curves of MK-based geopolymer cemented silty clay obtained from UCS tests are shown in Figure 2.
Figure 2(a) is the stress-strain curves of MK0 group at different curing times. The aforementioned figure reveals that with the increase of curing time, the peak stress increases while the stress decreases sharply after peak strain, and the corresponding failure modes change from plastic failure to brittle failure. Figure 2(b) illustrates that at $1 \mathrm{~d}$, the stress of MK6 group increases slowly with increasing axial strain compared with that for MK0, MK2, and MK4 group. With the increase of axial strain, the increase rate of MK2 group is higher compared with other groups.

3.2. UCS and Elasticity Modulus. UCS and elasticity modulus are two significant parameters to evaluate the resistance ability of MK-cemented silty clay subject to external loading. In this test, the peak stress is defined as the UCS, and the elasticity modulus $\left(E_{50}\right)$ is defined as the slope between the original point and 0.5 UCS. Test data of UCS and $E_{50}$ of MKbased geopolymer cemented silty clay under different $\mathrm{MK}$ contents and curing times are shown in Figure 3.

Figure 3 reveals that both the UCS and $E_{50}$ increase with the increase of curing time, and the increase rate shows obviously different at different curing time periods, specifically, the increase rate of UCS and $E_{50}$ from $1 \mathrm{~d}$ to $7 \mathrm{~d}$ is faster compared with that from $7 \mathrm{~d}$ to $28 \mathrm{~d}$. In addition, with the incorporation of MK, both the UCS and $E_{50}$ show first increase and then decrease, and the average values of UCS and $E_{50}$ of MK2 and MK4 groups are larger compared with that of MK0 group under the same curing time. However, both the UCS and $E_{50}$ of MK6 group are smaller than those of MK0 group, indicating that too much $\mathrm{MK}$ content weakens the property of MK-cemented silty clay. For example, at $28 \mathrm{~d}$, the average values of UCS and $E_{50}$ of MK2 group are 1.32 and 1.30 times compared with the control group MK0, respectively, agreeing with the previous study results [22]. However, these values of MK6 group are only 


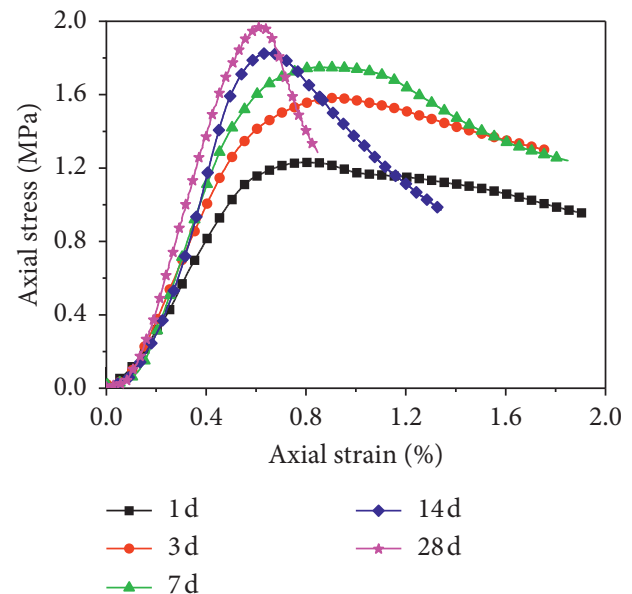

(a)

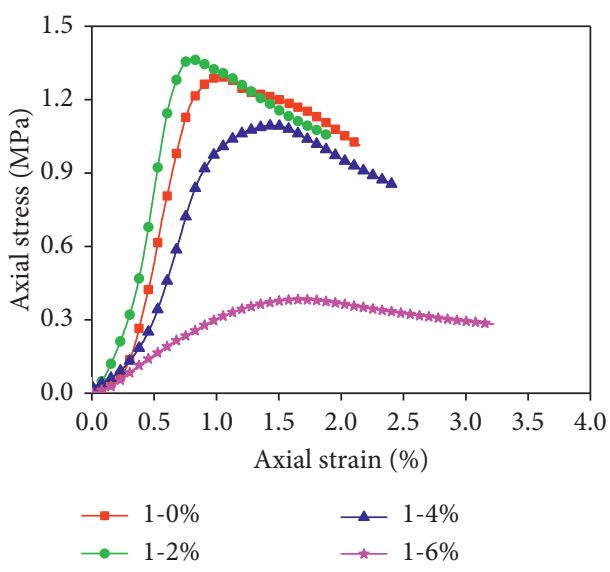

(b)

FIgURE 2: Typical stress-strain curves of MK-cemented silty clay. (a) MK0 at different curing times. (b) Curing time $1 \mathrm{~d}$ with different MK contents.

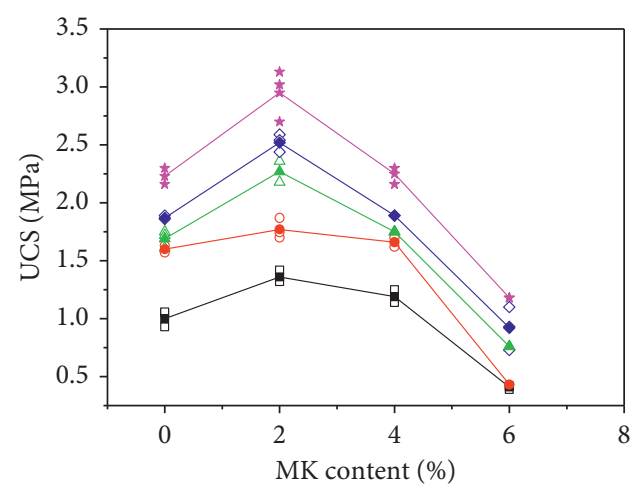

- $1 \mathrm{~d}$ original data $\rightarrow 1 \mathrm{~d}$ average value

- $3 \mathrm{~d}$ original data $\rightarrow 3 \mathrm{~d}$ average value

$\triangle 7 \mathrm{~d}$ original data $\_7 \mathrm{~d}$ average value

$\diamond 14 \mathrm{~d}$ original data $\rightarrow 14 \mathrm{~d}$ average value

* $28 \mathrm{~d}$ original data $\ldots 28 \mathrm{~d}$ average value

(a)

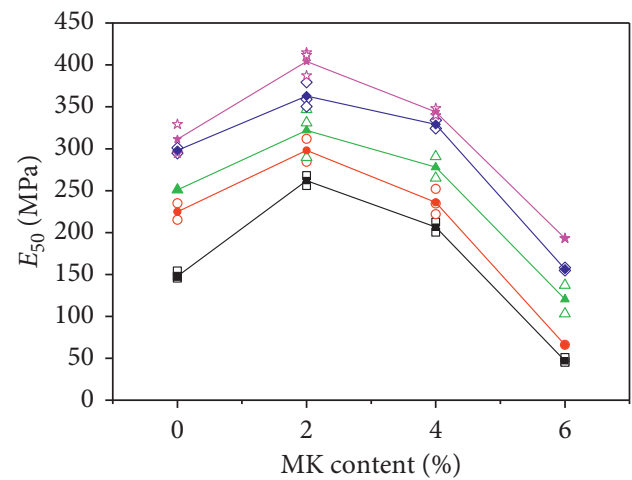

- $1 \mathrm{~d}$ original data $\rightarrow-1 \mathrm{~d}$ average value

- $3 \mathrm{~d}$ original data $\rightarrow 3 \mathrm{~d}$ average value

$\triangle 7 \mathrm{~d}$ original data $\_7 \mathrm{~d}$ average value

$\diamond 14 \mathrm{~d}$ original data $\rightarrow 14 \mathrm{~d}$ average value

* $28 \mathrm{~d}$ original data $\rightarrow 28 \mathrm{~d}$ average value

(c)

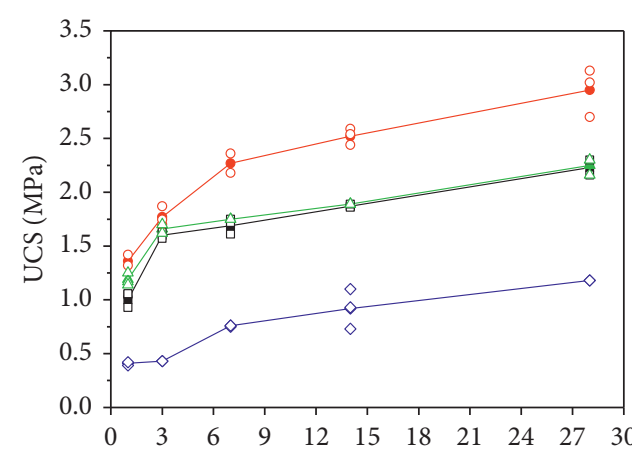

$\rightarrow$ MK0 average value $\square$ MK0 original data

- MK2 average value $\circ$ MK2 original data

$\leadsto$ MK4 average value $\triangle$ MK4 original data

$\rightarrow$ MK6 average value $\diamond$ MK6 original data

(b)

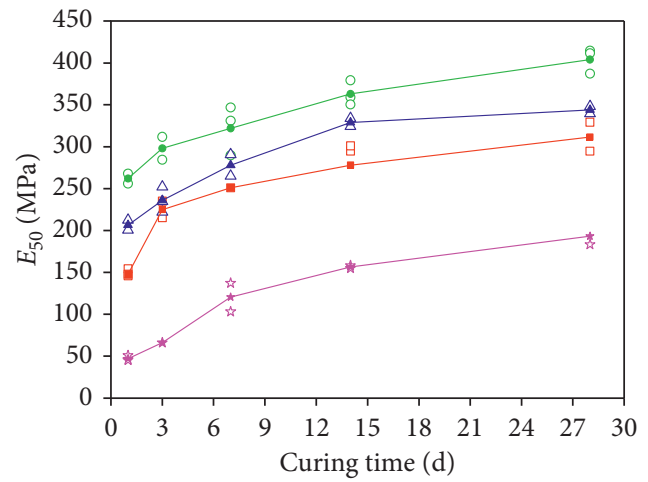

- MK0 original data $\rightarrow$ MK0 average value - MK2 original data - MK2 average value $\triangle$ MK4 original data $\leftarrow$ MK4 average value \& MK6 original data $\rightarrow$ MK6 average value

(d)

FIGURE 3: UCS and $E_{50}$ test results of MK-cemented silty clay. (a) UCS at different MK contents, (b) UCS at different curing times, (c) $E_{50}$ at different MK contents, and (d) $E_{50}$ at different curing times. 
0.53 and 0.59 times compared with MK0 group. Hence, the optimal mass ratio between MK and cement is $2: 13$ in this experiment, and the corresponding strength of MKcemented silty clay is the highest. As a contrast, Wang et al. [22] found a similar optimum mass ratio $(1: 6.5-1: 4)$ for CMK cemented silty soil, and $1: 4$ mass ratio was found for sandy soil [23]. Wu et al. [15] reported that the optimum mass ratio ranges from $1 / 3$ to $1 / 2$ for silt sand. The reactivity degree of geopolymer and cement is affected by test conditions. Hence, the difference between the above test results may be caused by the soil and MK types [38,39].

After a detailed evaluation of the changes in the UCS and $E_{50}$ data, to evaluate the effect of curing time on the mechanical property of MK-cemented silty clay, strength increase coefficient $\left(\zeta_{s}\right)$ and elasticity modulus increase coefficient $\left(\zeta_{\mathrm{e}}\right)$ are defined in this research and can be calculated as follows:

$$
\begin{gathered}
\zeta_{s}=\frac{U C S_{n}}{U C S_{28}} \times 100 \%, \\
\zeta_{e}=\frac{E_{50 n}}{E_{50,28}} \times 100 \%,
\end{gathered}
$$

where $\mathrm{UCS}_{n}$ and $\mathrm{UCS}_{28}$ are the unconfined compressive strength of MK-cemented silty clay at curing time of $n \mathrm{~d}$ and $28 \mathrm{~d}$, respectively. $E_{50 n}$ and $E_{50,28}$ are the elasticity modulus of MK-cemented silty clay at curing time of $n \mathrm{~d}$ and $28 \mathrm{~d}$, respectively.

Figure 4 presents the calculated results of $\zeta_{\mathrm{s}}$ and $\zeta_{\mathrm{e}}$ at different curing times. It is clearly noticed that (1) compared with MK0, MK2, and MK4 groups, MK6 group shows relatively small values of $\zeta_{s}$ and $\zeta_{\mathrm{e}}$ from $1 \mathrm{~d}$ to $7 \mathrm{~d}$ because there have been no sufficient hydration products to react with geopolymer. For MK6 group, the values of $\zeta_{\mathrm{s}}$ at $1 \mathrm{~d}$ and $3 \mathrm{~d}$ are $21.9 \%$ and $40.6 \%$, respectively, which are much lower than those of other three groups; (2) the values of $\zeta_{\mathrm{s}}$ and $\zeta_{\mathrm{e}}$ for MK2 and MK4 groups are higher than those of MK0 group at $1 \mathrm{~d}$; however, the values of $\zeta_{\mathrm{s}}$ and $\zeta_{\mathrm{e}}$ are close to MK0, MK2, and MK4 groups from $3 \mathrm{~d}$ to $28 \mathrm{~d}$. In addition, $\zeta_{\mathrm{s}}$ can reach $75.8 \%$ to $77.8 \%$ at $7 \mathrm{~d}$ for MK0, MK2, and MK4 groups, and the corresponding values of $\zeta_{\mathrm{e}}$ range from $79 \%$ to $80.8 \%$, indicating that these three groups show better early strength and deformation resistance ability.

In ground treatment and foundation supporting design engineering practice, the ratio between $E_{50}$ and UCS is an important evaluation parameter which should lie in the range of 100 to 120 according to the standard JGJ 79-2012. Hence, the relationship between $E_{50}$ and UCS at different curing times in the present study and other test results [40] are collected and shown in Figure 5. Yilmaz and Ozaydin [40] found that the ratio between $E_{50}$ and UCS of belite cement (BC) clay and ordinary Portland cement (OPC) clay were 79 and 107, respectively. The ratio between $E_{50}$ and UCS lied in the range of 60 to 145 in the present study. In addition, most of the test results at $28 \mathrm{~d}$ satisfy the standard request.

3.3. NMR Results. The porosity of MK-based geopolymer cemented silty clay with different test conditions are
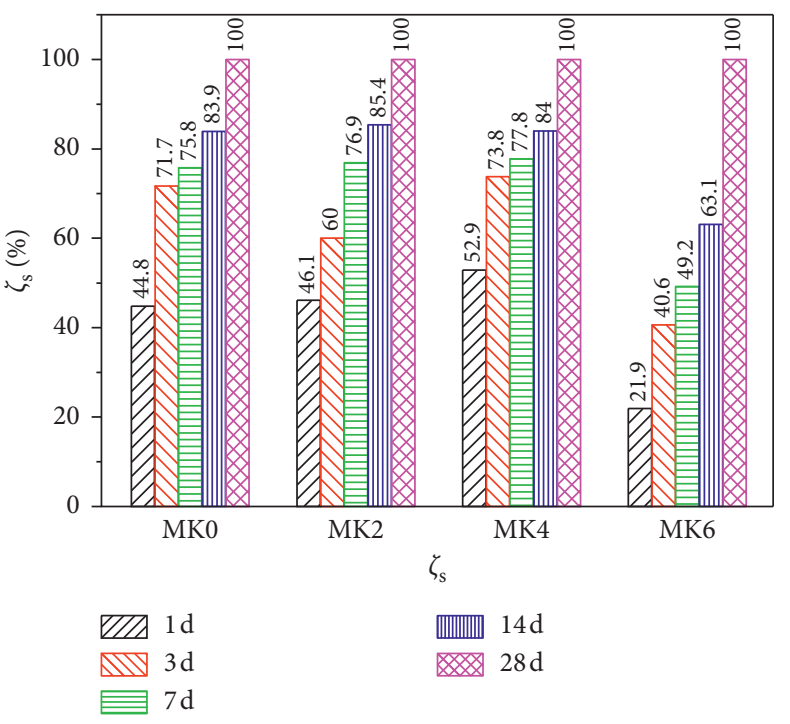

(a)
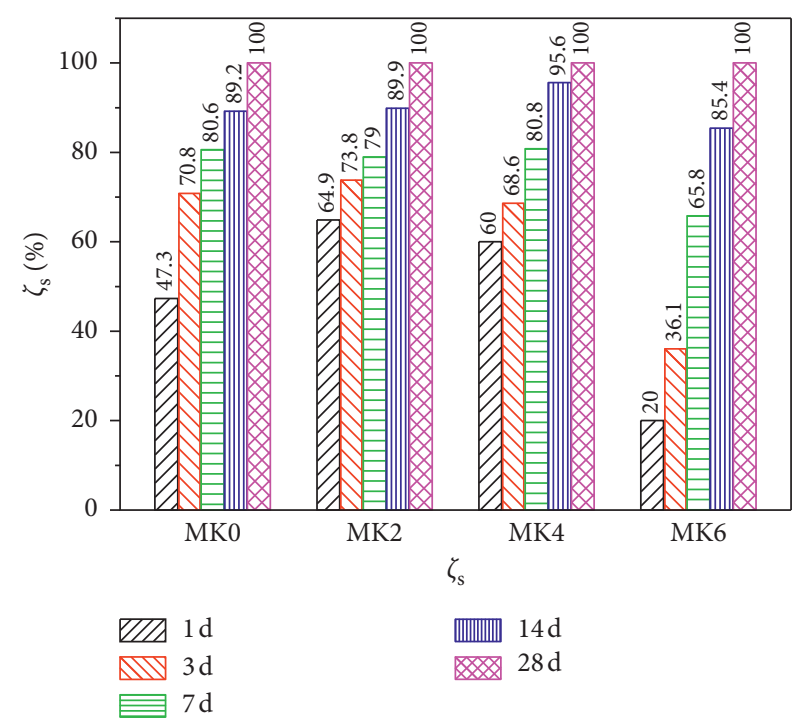

(b)

FIgURE 4: Test results of $\zeta_{\mathrm{s}}$ and $\zeta_{\mathrm{e}}$ of MK-cemented silty clay at different curing times. (a) $\zeta_{\mathrm{s}}$ and (b) $\zeta_{\mathrm{e}}$.

measured by NMR. The obtained NMR data are presented in Table 3 . The test samples with $6 \% \mathrm{MK}$ content at curing time of $1 \mathrm{~d}, 3 \mathrm{~d}$, and $7 \mathrm{~d}$ fall to pieces during saturated process because of their low strength. Moreover, the relationships among porosity, UCS, and $E_{50}$ are shown in Figure 6.

Table 3 reveals that at the same curing time, MK2 group shows the smallest porosity values compared with other three groups. Moreover, the porosity decreases with increasing curing time at the same MK content, which is attributed to the pozzolanic reaction between geopolymer, cement, and water [41]. Figure 6 illuminates that both UCS and $E_{50}$ of MK-based geopolymer cemented silty clay decrease with the increase of porosity and exhibit a linear correlation. In this test, the porosity of MK-based geopolymer cemented soil increases from $21.22 \%$ to $26.21 \%$, the corresponding values of UCS decreases from $2.95 \mathrm{MPa}$ to 


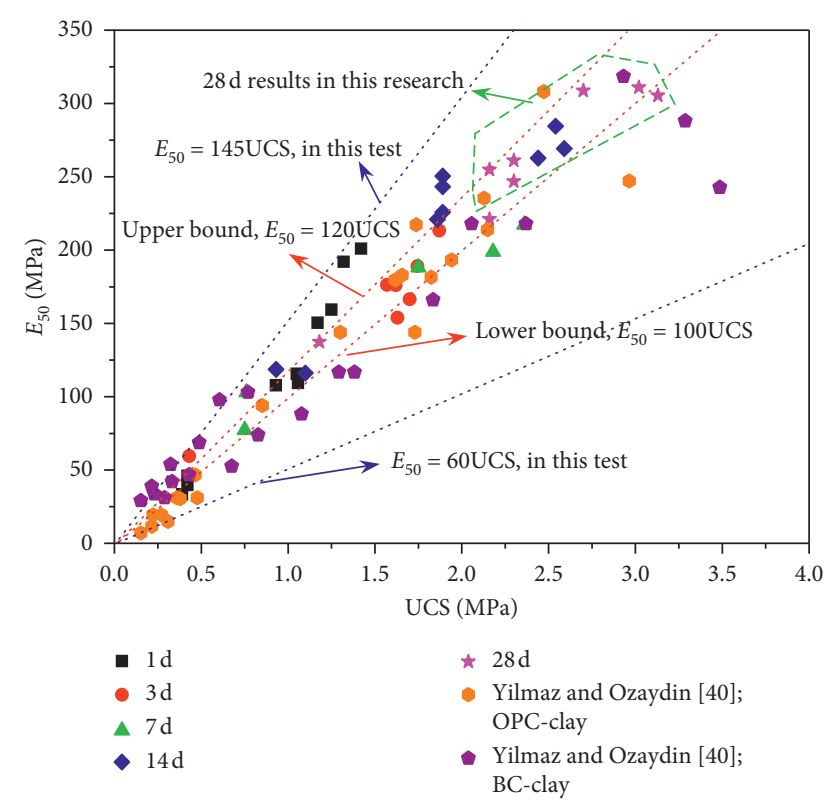

FIGURE 5: Test results between $E_{50}$ and UCS of MK-cemented silty clay.

Table 3: Porosity results of MK-cemented silty clay.

\begin{tabular}{lcc}
\hline Curing time $(\mathrm{d})$ & MK content $(\%)$ & Porosity $(\%)$ \\
\hline \multirow{4}{*}{1} & 0 & 25.84 \\
& 2 & 22.92 \\
& 4 & 26.21 \\
& 6 & - \\
\hline \multirow{4}{*}{3} & 0 & 24.77 \\
& 2 & 22.52 \\
& 4 & 25.80 \\
7 & 6 & - \\
\hline \multirow{4}{*}{14} & 0 & 24.23 \\
& 2 & 21.88 \\
& 4 & 25.44 \\
& 6 & - \\
\hline \multirow{3}{*}{28} & 0 & 23.85 \\
& 2 & 21.67 \\
& 4 & 24.78 \\
& 6 & 27.89 \\
\hline
\end{tabular}

$0.92 \mathrm{MPa}$, while it decreases from $303 \mathrm{MPa}$ to $117 \mathrm{MPa}$ for $E_{50}$, and the decreasing degrees of them are $69.5 \%$ and $61.4 \%$, respectively.

3.4. SEM Analysis. The microstructure can reflect the variations of physical and mechanical properties of MK-based geopolymer cemented silty clay $[15,22,23]$. SEM tests are conducted to observe the microstructure characteristic and hydration products in the bulk binder phase.

Figure 7 shows the SEM images of samples at curing time of $28 \mathrm{~d}$ with different $\mathrm{MK}$ contents at $800 \mathrm{x}$ amplification.

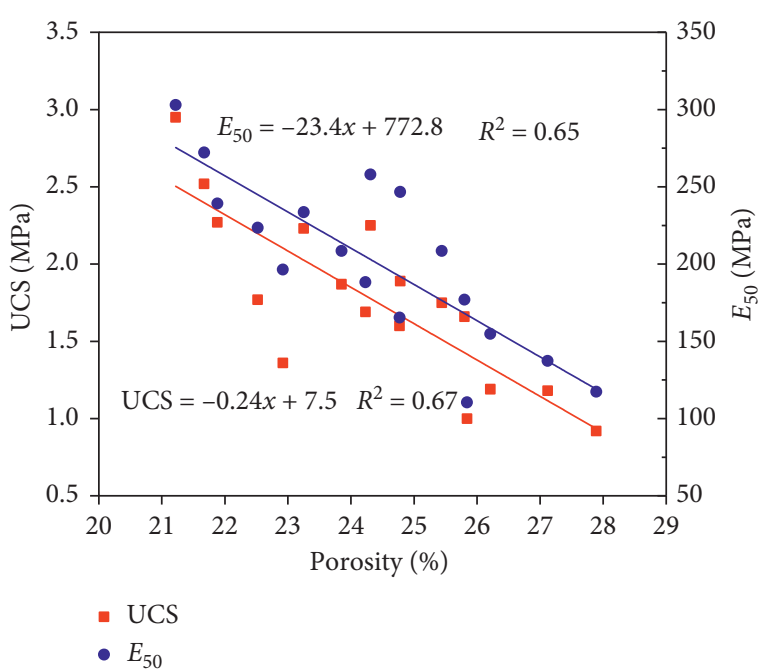

FIGURE 6: Relationships between porosity and of UCS and E50.

MK content has a significant influence on the microstructure characteristic of MK-based geopolymer cemented soil. Figure 7(a) is the representative SEM images of MK0 group. It can be found that the microstructure of mixture without $\mathrm{MK}$ is loose and not uniform, and some cracks and pores are observed between soil particles. As a contrast, Figure 7(b) demonstrates that with the incorporation of $\mathrm{MK}$, the microstructure of MK2 group is relatively denser and uniform, while the number of cracks and pores clearly decrease. This finding primary attributes to accelerate cement hydration caused by secondary reaction between geopolymer and hydration product of cement [29]. For the MK4 group, there exist more cracks and pores compared with that of MK2 group, while better than that of MK0 group. Furthermore, widely distributed cracks and pores are found for MK6 group, which also exhibits the loosest microstructure. Hence, $6 \%$ MK content has a negative effect on MK-based geopolymer cemented silty clay, which reduces its UCS and $E_{50}$. By comparing the microstructure characteristics of four groups, it is obvious that the microstructure of the sample modified by $2 \% \mathrm{MK}$ is most homogeneous and dense.

Figure 8 represents SEM images of MK2 group with different curing times at $800 \mathrm{x}$ and $12000 \mathrm{x}$ amplification, respectively. The SEM images at $800 \mathrm{x}$ amplification can easily observe the cracks and pores inside, while the microcracks, micropores, and hydration products such as C-S-H, which improve the property of MK cemented soil [41], can be observed at 12000x amplification. As shown in Figure $8(\mathrm{a})$, loose microstructure and lots of cracks and pores are found at $1 \mathrm{~d}$, meanwhile, a small quantity of C-S-H is observed on the surface of the soil particles because there has been no sufficient time for cement hydration reaction. At $3 \mathrm{~d}$ and $7 \mathrm{~d}$, due to the accelerate cement hydration caused by geopolymer, a number of C-S-H can be obviously found and some of them have filled in the pores, while the size of micropores and microcracks decreases with increasing curing time, as shown in Figures $8(\mathrm{~b})$ and $8(\mathrm{c})$. From Figure $8(d)$ it can be clearly noticed that no obvious cracks can be observed at curing time of $14 \mathrm{~d}$, and a number 


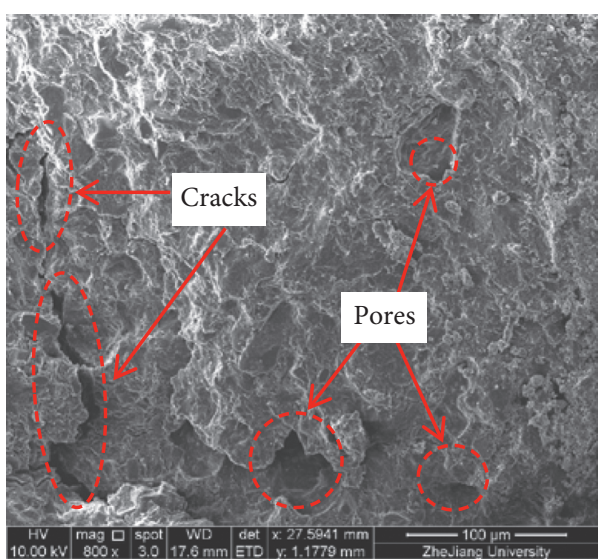

(a)

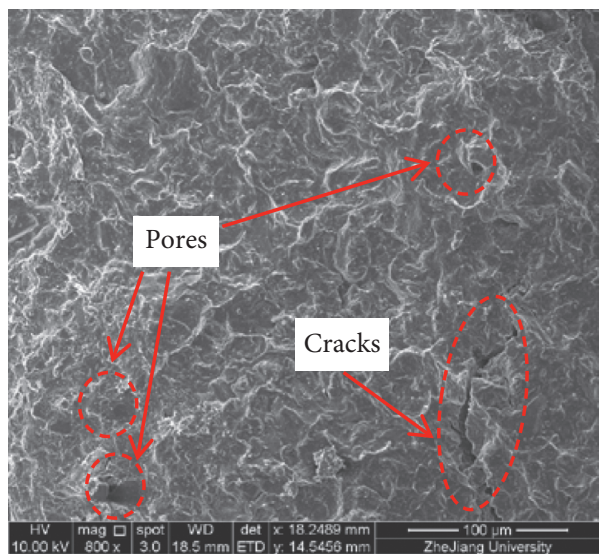

(c)

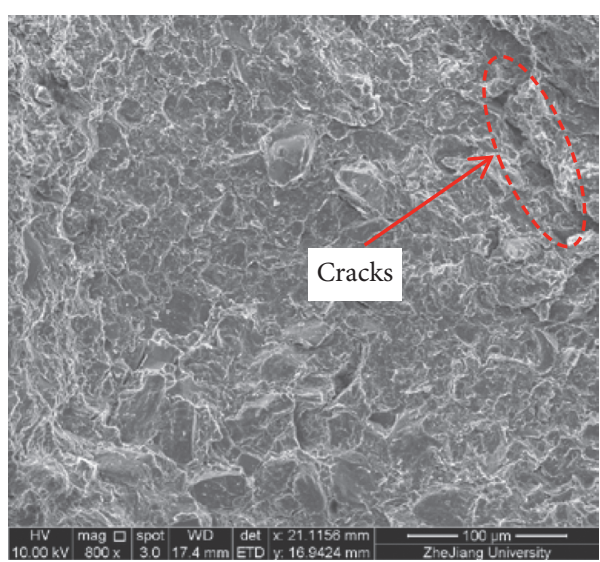

(b)

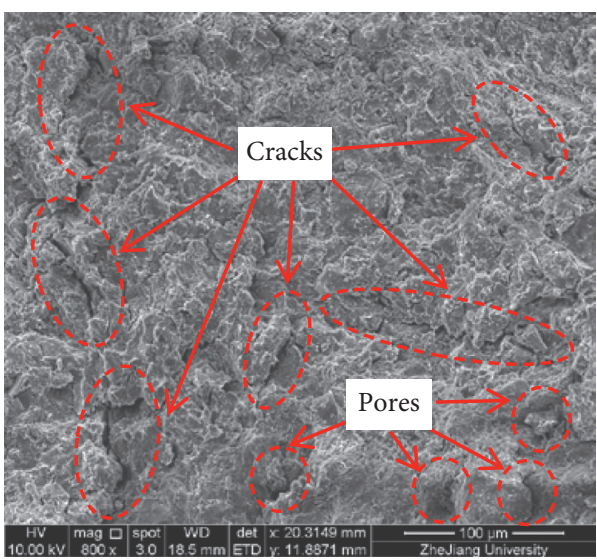

(d)

FIgure 7: SEM images of at $28 \mathrm{~d}$ with different MK contents. (a) MK0, (b) MK2, (c) MK4, and (d) MK6.

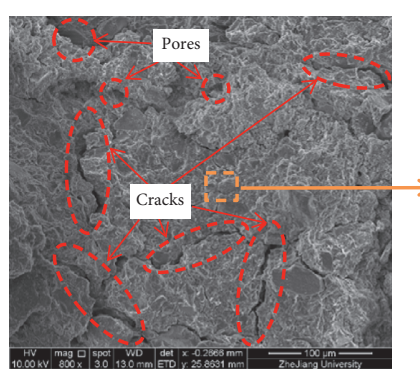

(a)

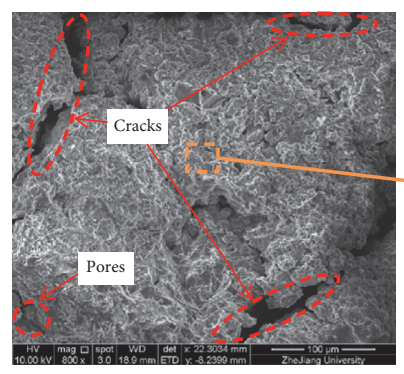

(c)
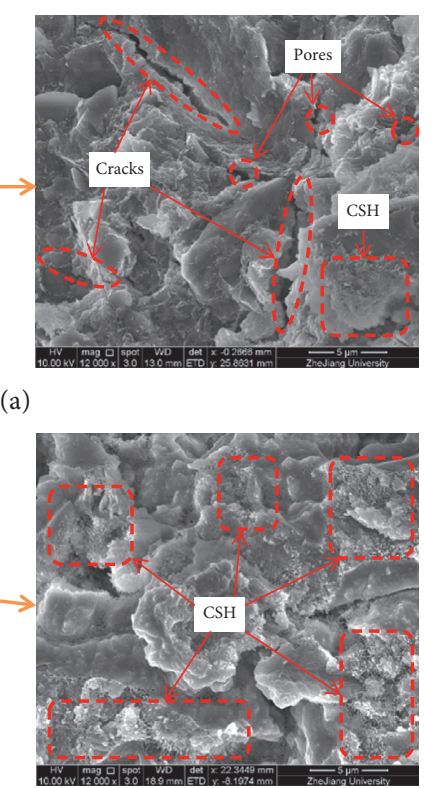
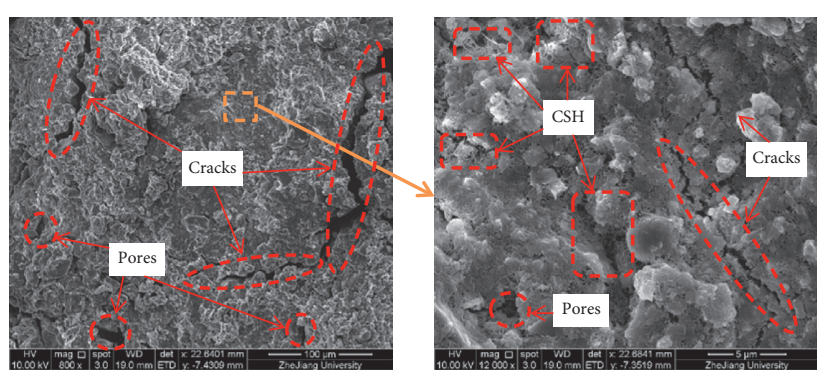

(b)
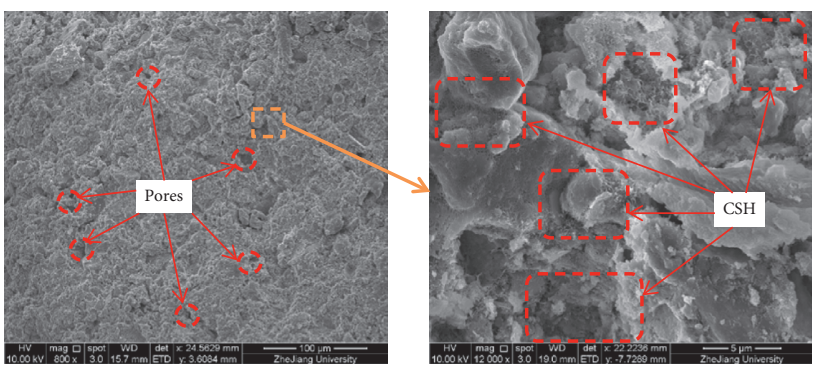

(d)

Figure 8: Continued. 


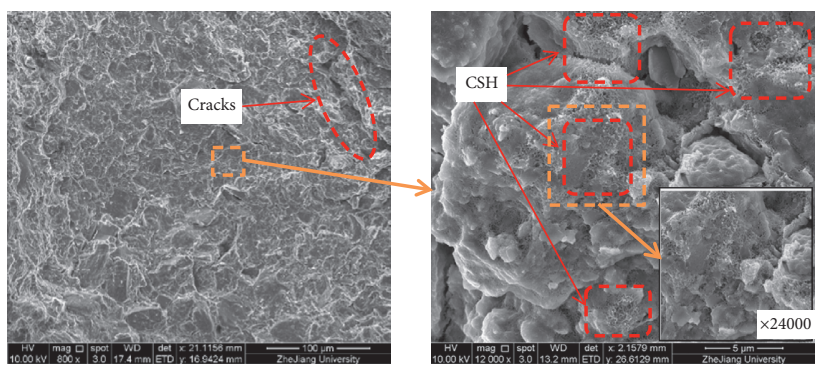

(e)

FIGURE 8: SEM images of MK2 group with different curing times. (a) $1 \mathrm{~d}$, (b) $3 \mathrm{~d}$, (c) $7 \mathrm{~d}$, (d) $14 \mathrm{~d}$, and (e) $28 \mathrm{~d}$.

quantity of C-S-H has covered most of the soil particles and connected with each other. Figure $8(\mathrm{e})$ illustrates that the structure of MK2 at $28 \mathrm{~d}$ is denser, while both macropores and micropores are filled with C-S-H, thereby improving its macromechanical properties, such as strength and elastic modulus.

\section{Conclusions}

(1) Both the UCS and $E_{50}$ increase with the increase in curing time, and the increase rate from $1 \mathrm{~d}$ to $7 \mathrm{~d}$ is faster compared with that from $7 \mathrm{~d}$ to $28 \mathrm{~d}$. With the incorporation of MK, both the UCS and $E_{50}$ show the regular first increase and then decrease. 2\% MK content shows the highest UCS and $E_{50}$ in this test, and the average values of them are 1.32 and 1.30 times compared with MK0 group at $28 \mathrm{~d}$, respectively. In addition, the ratio between $E_{50}$ and UCS lied in the range of 60 to 145 in the present study, and most of the test results at $28 \mathrm{~d}$ satisfy the standard request.

(2) NMR results indicate that at the same curing time, the MK2 group shows the lowest porosity compared with other three groups. Moreover, the porosity decreases with increasing curing time. Both the UCS and $E_{50}$ of the MK-based geopolymer cemented silty clay decrease with the increase of porosity and exhibit a linear correlation. In this test, the porosity of MK-based geopolymer cemented silty clay increases from $21.22 \%$ to $26.21 \%$, the corresponding values of UCS decreases from $2.95 \mathrm{MPa}$ to $0.92 \mathrm{MPa}$, while it decreases from $303 \mathrm{MPa}$ to $117 \mathrm{MPa}$ for $E_{50}$.

(3) SEM results reveal that the microstructure of the sample modified by $2 \% \mathrm{MK}$ is most homogeneous and dense compared with other MK content groups. With the increasing curing time, the size of both micropores and microcracks decrease which contributes to improving its strength and elastic modulus.

\section{Data Availability}

The datasets generated and analyzed during the current study are available from the corresponding author on reasonable request.

\section{Conflicts of Interest}

The authors declare that there are no conflicts of interest regarding the publication of this paper.

\section{Acknowledgments}

This research received financial support from Anhui Provincial Natural Science Foundation (no. 1908085QE212) and Doctoral Fund Project of Anhui University of Science and Technology (nos. 11695 and 13190025). The authors thank the Engineering Research Center of Underground Mine Construction, Ministry of Education, Anhui University of Science and Technology, and State Key Laboratory of Mining Response and Disaster Prevention and Control in Deep Coal Mine, for providing the experiment conditions.

\section{References}

[1] F. Xu, H. Wei, W. X. Qian, and T. B. Cai, "Composite alkaline activator on cemented soil: multiple tests and mechanism analyses," Construction and Building Materials, vol. 188, pp. 433-443, 2018.

[2] K. Yao, W. Wang, N. Li, C. Zhang, and L. X. Wang, "Investigation on strength and microstructure characteristics of nano-MgO admixed with cemented soft soil," Construction and Building Materials, vol. 206, pp. 160-168, 2019.

[3] N. C. Consoli, D. A. Rosa, R. C. Cruz, and A. D. Rosa, "Water content, porosity and cement content as parameters controlling strength of artificially cemented silty soil," Engineering Geology, vol. 122, no. 3-4, pp. 328-333, 2011.

[4] A. J. Choobbasti, H. Tavakoli, and S. S. Kutanaei, "Modeling and optimization of a trench layer location around a pipeline using artificial neural networks and particle swarm optimization algorithm," Tunnelling and Underground Space Technology, vol. 40, pp. 192-202, 2014.

[5] C. A. Anagnostopoulos, "Strength properties of an epoxy resin and cementstabilized silty clay soil," Applied Clay Science, vol. 114, pp. 517-529, 2015.

[6] S. Kolias, V. Kasselouri-Rigopoulou, and A. Karahalios, "Stabilisation of clayey soils with high calcium fly ash and cement," Cement and Concrete Composites, vol. 27, no. 2, pp. 301-313, 2005.

[7] J. M. Ortega, M. D. Esteban, I. Sanchez, and M. A. Climent, "Performance of sustainable fly ash and slag cement mortars exposed to simulated and real in situ mediterranean conditions along 90, warm season days," Materials, vol. 10, no. 11, p. 1254, 2017. 
[8] F. Pacheco-Torgal and S. Jalali, "Reusing ceramic wastes in concrete," Construction and Building Materials, vol. 24, no. 5, pp. 832-838, 2010.

[9] A. M. Rashad and S. R. Zeedan, "The effect of activator concentration on the residual strength of alkali-activated fly ash pastes subjected to thermal load," Construction and Building Materials, vol. 25, no. 7, pp. 3098-3107, 2011.

[10] E. Benhelal, G. Zahedi, E. Shamsaei, and A. Bahadori, "Global strategies and potentials to curb $\mathrm{CO}_{2}$ emissions in cement industry," Journal of Cleaner Production, vol. 51, pp. 142-161, 2013.

[11] F. Pelisser, E. L. Guerrino, M. Menger, M. D. Michel, and J. A. Labrincha, "Micromechanical characterization of metakaolin-based geopolymers," Construction and Building Materials, vol. 49, pp. 547-553, 2013.

[12] A. M. Rashad, "Alkali-activated metakaolin: a short guide for civil engineer-an overview," Construction and Building Materials, vol. 41, pp. 751-765, 2013.

[13] A. Al-Swaidani, I. Hammoud, and A. Meziab, "Effect of adding natural pozzolana on geotechnical properties of limestabilized clayey soil," Journal of Rock Mechanics and Geotechnical Engineering, vol. 8, no. 5, pp. 714-725, 2016.

[14] H. Mola-Abasi and I. Shooshpasha, "Influence of zeolite and cement additions on mechanical behavior of sandy soil," Journal of Rock Mechanics and Geotechnical Engineering, vol. 8, no. 5, pp. 746-752, 2016.

[15] Z. L. Wu, Y. F. Deng, S. Y. Liu, Q. W. Liu, Y. G. Chen, and F. S. Zha, "Strength and micro-structure evolution of compacted soils modified by admixtures of cement and metakaolin," Applied Clay Science, vol. 127-128, pp. 44-51, 2016.

[16] T. W. Zhang, X. B. Yue, Y. F. Deng, D. W. Zhang, and S. Y. Liu, "Mechanical behavior and micro-structure of cement-stabilised marine clay with a metakaolin agent," Construction and Building Materials, vol. 73, pp. 51-57, 2014.

[17] K. G. Kolovos, P. G. Asteris, D. M. Cotsovos, E. Badogiannis, and S. Tsivilis, "Mechanical properties of soilcrete mixtures modified with metakaolin," Construction and Building Materials, vol. 47, pp. 1026-1036, 2013.

[18] J. H. Xie, W. Chen, J. J. Wang, C. Fang, B. X. Zhang, and F. Liu, "Coupling effects of recycled aggregate and GGBS/ metakaolin on physicochemical properties of geopolymer concrete," Construction and Building Materials, vol. 226, pp. 345-359, 2019.

[19] Y. F. Deng, X. B. Yue, S. Y. Liu, Y. G. Chen, and D. W. Zhang, "Hydraulic conductivity of cement-stabilized marine clay with metakaolin and its correlation with pore size distribution,” Engineering Geology, vol. 193, pp. 146-152, 2015.

[20] A. J. Choobbasti and S. S. Kutanaei, "Microstructure characteristics of cement-stabilized sandy soil using nanosilica," Journal of Rock Mechanics and Geotechnical Engineering, vol. 9, no. 5, pp. 981-988, 2017.

[21] K. Wianglor, S. Sinthupinyo, M. Piyaworapaiboon, and A. Chaipanich, "Effect of alkali-activated metakaolin cement on compressive strength of mortars," Applied Clay Science, vol. 141, pp. 272-279, 2017.

[22] H. Wang, X. Y. Li, Y. Cheng, Y. F. Zhang, and X. H. Bai, "Effects of coal-bearing metakaolin on the compressive strength and permeability of cemented silty soil and mechanisms," Construction and Building Materials, vol. 186, pp. 174-181, 2018.

[23] L. H. Wang, X. Y. Li, Y. Cheng, and X. H. Bai, "Effects of coalmetakaolin on the properties of cemented sandy soil and its mechanisms," Construction and Building Materials, vol. 166, pp. 592-600, 2018.

[24] F. G. M. Aredes, T. M. B. Campos, J. P. B. MacHado, K. K. Sakane, G. P. Thim, and D. D. Brunelli, "Effect of cure temperature on the formation of metakaolinite-based geopolymer," Ceramics International, vol. 41, no. 6, pp. 7302-7311, 2015.

[25] F. Slaty, H. Khourya, H. Rahier, and J. Wastiels, "Durability of alkali activated cement produced from kaolinitic clay," Applied Clay Science, vol. 104, pp. 229-237, 2015.

[26] M. o. C. o. PRC., Code for Investigation of Geotechnical Engineering, Architecture and Building Press, Beijing, China, 2009.

[27] M. o .C. o. PRC., Technical Code for Ground Treatment of Buildings, China Architecture Industry Press, Beijing, China, 2012.

[28] K. Gao, K. L. Lin, D. Y. Wang et al., "Effects $\mathrm{SiO}_{2} / \mathrm{Na}_{2} \mathrm{O}$ molar ratio on mechanical properties and the microstructure of nano- $\mathrm{SiO}_{2}$ metakaolin-based geopolymers," Construction and Building Materials, vol. 53, pp. 503-510, 2014.

[29] Y. F. Deng, Z. L. Wu, S. Y. Liu et al., "Influence of geopolymer on strength of cement-stabilized soils and its mechanism," Chinese Journal of Geotechnical Engineering, vol. 3, pp. 446-453, 2016.

[30] C. S. Poon, L. Lam, S. C. Kou, Y. L. Wong, and R. Wong, "Rate of pozzolanic reaction of metakaolin in high-performance cement pastes," Cement and Concrete Research, vol. 31, no. 9, pp. 1301-1306, 2001.

[31] W. P. Halperin, J. Y. Jehng, and Y. Q. Song, "Application of spin-spin relaxation to measurement of surface area and pore size distributions in a hydrating cement paste," Magnetic Resonance Imaging, vol. 12, no. 2, pp. 169-173, 2003.

[32] V. Bortolotti, P. Fantazzini, R. Mongiorgi, S. Sauro, and S. Zanna, "Hydration kinetics of cements by time-domain nuclear magnetic resonance: application to portland-cementderived endodontic pastes," Cement and Concrete Research, vol. 42, no. 3, pp. 577-582, 2012.

[33] A. Valori, P. J. McDonald, and K. L. Scrivener, "The morphology of C-S-H: lessons from $1 \mathrm{H}$ nuclear magnetic resonance relaxometry," Cement and Concrete Research, vol. 49, pp. 65-81, 2013.

[34] J. M. Xiao and H. H. Fan, "Application of solid-state nuclear magnetic resonance techniques in research of cement and hydration products," Journal of Materials Science \& Engineering, vol. 1, pp. 166-172, 2016.

[35] Y. Wang, Q. Yuan, D. H. Deng, T. Ye, and L. Fang, "Measuring the pore structure of cement asphalt mortar by nuclear magnetic resonance," Construction and Building Materials, vol. 137, pp. 450-458, 2017.

[36] M. Arif, V. Gupta, H. Choudhary, S. Kumar, and P. Basu, "Performance evaluation of cement concrete containing sandstone slurry," Construction and Building Materials, vol. 184, pp. 432-439, 2018.

[37] Z. F. Zhao, M. Benzerzour, N. Abriak, D. Damidot, and L. Courard, "Use of uncontaminated marine sediments in mortar and concrete by partial substitution of cement," Cement and Concrete Composites, vol. 93, pp. 155-162, 2018.

[38] M. Murat, "Hydration reaction and hardening of calcined clays and related minerals: II. Influence of mineralogical properties of the raw-kaolinite on the reactivity of metakaolinite," Cement and Concrete Research, vol. 13, no. 4, pp. 511-518, 1983.

[39] G. Kakali, T. Perraki, S. Tsivilis, and E. Badogiannis, "Thermal treatment of kaolin: the effect of mineralogy on the pozzolanic activity," Applied Clay Science, vol. 20, no. 1-2, pp. 73-80, 2001.

[40] Y. Yilmaz and V. Ozaydin, "Compaction and shear strength characteristics of colemanite ore waste modified active belite cement stabilized high plasticity soils," Engineering Geology, vol. 155, pp. 45-53, 2013.

[41] S. Barbhuiya, P. Chow, and S. Memon, "Microstructure, hydration and nanomechanical properties of concrete containing metakaolin," Construction and Building Materials, vol. 95, pp. 696-702, 2015. 